\title{
RELATIONSHIP DERIVATIVES FINANCIAL MARKETS, MONEY AND STOCK MARKETS AS A SUBSYSTEM OF FINANCIAL MARKET
}

\author{
Yulia YELNIKOVA ${ }^{1}$, \\ Sumy National Agrarian University, Ukraine
}

\begin{abstract}
Under conditions of intensive strengthening of globalization of world financial markets and deepening of the crisis, the main source of which are financial markets, financial derivatives market is rapidly developing. In such circumstances, we observe very active growing demand for tools, the main purpose of which is to reduce the financial risk - derivatives. Outlined trend has also involved Ukraine. In this connection, there is an objective need to develop estimate the interconnection of the money and stock markets and derivatives market. It should be kept in mind that achieving the outlined goal is possible only under condition of the full understanding of the scientific and methodological principles of the development of these markets. Purpose is to estimate the interconnection of the money and stock markets and derivatives market by building a mathematical model of system of structural equations that will promote the compilation of scientifically based program of derivatives market. Methodology. By using methods of economic-mathematical modelling were estimated the degree of influence of studied markets factors on financial derivatives market development and by changing this or that factor were predicted future trends of its operations. Results of the survey showed the current state and problems of derivatives market functioning. At the same time, our study allowed us to talk, that factors of the money and stock markets have a different impact on the derivatives market. So, the majority of money market factors have a reverse influence on the development of derivatives market. Instead, the stock market has a direct influence. Practical implications. The proposed scientific and methodical approach to evaluating the impact of factors on the derivatives market allows: influenced by different factors; to conduct a qualitative interpretation of the quantitative changes in the level of market development; to form a complete system of state regulation of derivatives aimed at rational its development. Value/originality. The approach to the structural modelling of money and stock markets impact on market of derivatives allows not only to determine the effect of each factor, but also to form a complete system of state regulation of derivatives aimed at rational its development.
\end{abstract}

Key words: financial derivatives market, stock market, money market, financial market, financial depth.

JEL Classification: G17, E 44, C 58

\section{1. Введение}

Сегодня механизм регулирования и надзора рынка производных финансовых инструментов (Аалее - РПФИ) характеризируется большим количеством проблем, которые свидетельствуют о необходимости пересмотра фундаментальных основ организации этой системы, а именно концентрации внимания на аспектах устойчивости финансовой системы в целом, а не на ее определенных финансовых учреждениях. Функционирование РПФИ невозможно рассматривать без исследования факторного воздействия, которое осуществляется фондовым и Аенежным рынками. Аинамика показателей этих рынков вызывает изменения в отдельных структурных элементах финансового рынка, одним из которых есть РПФИ. Поэтому, с целью определения современных тенденций и перспективных направлений развития РПФИ на ближайший период необходимо применить методы экономико-математического моделирования, которые позволяют оценить степень влияния каждого фактора исследуемых рынков на развитие РПФИ и спрогнозировать буАущие тенАенции его функционирования путем изменения того или иного фактора. Таким образом, целью моделирования влияния фондового и денежного рынков на РПФИ есть построение математической модели с помощью системы структурных уравнений, явмяется основанием Аля составмения научно обоснованных программ развития РПФИ.

\section{2. Взаимосвязь факторов Аенежного рынка и РПФИ}

В результате использования метода экспертного оценивания в качестве показателей, которые характеризуют развитие Аенежного рынка, было выбрано

Corresponding author:

${ }^{1}$ Department of Economic Control and Audit, Sumy National Agrarian University.

E-mail: yuyelnikova@gmail.com 
глубину финансового рынка, индекс реального эффективного обменного курса (Аалее - ИРЭОК), реальная процентная ставка, Аефмятор ВВП и глобальный индекс капитала S\&P GEI.

Показатемь «глубина финансового рынка (financial depth) характеризует связь между насыщенностью экономики финансовыми ресурсами и темпами экономического роста (Poliukhovych, 2011). Этот показатель довольно часто используют Аля определения влияния развития финансового рынка на экономическую систему государства в целом. В последние года рост количества финансовых продуктов-инноваций с высоким уровнем риска, существование встроенной инфмяционной спирали, наращивание объемов секьюритизированных активов, господство миберальной монетарной Аоктрины вызвали увеличение глубины финансового сектора и отрыв его от реального, тем самым создавая преАпосылки Аля возникновения кризисов и цикличности финансового рынка в целом и РПФИ в частности в будущем. Так, в периоА кризиса 2007-2009 гг. в круговороте товарно-Аенежно-финансовых потоков наблюдается снижение избыточной Аоли финансовой нагрузки в виде «финансовых пузырей» и система кругооборота капитала возвращается к равновесному состоянию. ОАнако после кризисных событий благодаря «эффекту отскока» произошио восстановмение глубины финансового сектора на уровне, превышающем докризисные. Таким образом, этот показатель имеет иинейную связь с номинацьной стоимостью биржевых и внебиржевых ПФИ, поскольку характеризует уровень развития финансового рынка.

Такую же направленность имеет связь межАу ИРЭОК и номинальной стоимостью биржевых и внебиржевых ПФИ, поскольку как инструмент хеАжирования ПФИ позволяют нивелировать валютный риск, что особенно актуально сегодня.

Реальный эффективный обменный курс - расчетный валютный курс, который явмяется индикатором изменения ценовой конкурентоспособности отечественных товаров по отношению к продукции основных торговых партнерах страны (Bezpiatov, 2004). ИРЭОК явмяется индикатором изменения ценовой конкурен-

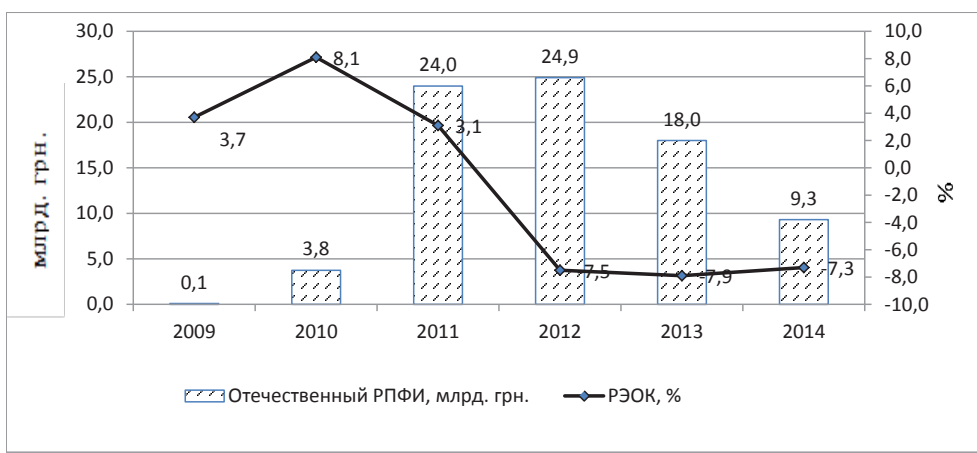

Рис. 1. Аинамика объема отечественного рынка ПФИ и РЭОК за 2009-2014 гг. (National Commission on Securities and Stock Market, 2015) тоспособности страны в межАународной торговле. Экономическое содержание ИРЭОК заключается в отображении изменения обменного курса, откорректированного на уровень инфмяции в странах - торговых партнерах. Факторами, влияющими на динамику ИРЭОК, являются: значение номинального обменного курса к валютам стран-партнеров и соотношение уровня инфмяции в стране до масштаба цен в странах-партнерах.

Итак, значительные колебания этого показателя вызывают изменения объемов торгов на рынке ПФИ, носящие как спекумятивный так и хеджированный характер (рис. 1).

Согласно данным, представленным на рисунке 1, в 2012 году наблюдается впервые за четыре года девальвация РЭОК, что сопровожАается значительным увемичением объемов торов на рынке ПФИ по сравнению с предыдущими годами когда была ревальвация РЭОК.

Кроме этого, растет также спекумятивный спрос на эти инструменты, поскольку участники имеют реальный шанс получить прибыль от изменения обменного курса. Так, сегодня, в периоА высоких темпов инфмяции и массовых кризисных явмений во всех сферах экономики, оАним из Аейственных инструментов явцяется установиение плавающего обменного курса. Аля НБУ, в процессе осуществления монетарной политики, в первую очередь, основной задачей остается инфмяционное таргетирование. Эффект от изменений курсовой политики Аля инфмяции будет более существенным, чем от регулирования Аругих монетарных параметров, что обусловлено более сильным взаимосвязью межАу указанными факторами. В связи с чем, коммерческие банки активно используют валютные Аеривативы с целью обеспечения нормальной Аиквидности, условия и ограничения обращения которых регламентирует Постановление НБУ «Об утвержАении Положения о порядке и условиях торговли иностранной валютой» от 10.08.2005 № 281 (Prymostka, 2001).

В свою очереАь, реальная процентная ставка имеет обратную связь с объемами торговли на рынке ПФИ, поскольку в случае увеличения уровня реальной процентной ставки растут объемы как прямых, так и портфельных инвестиций, что, в свою очередь, вызывает утечка денежных среАств с РПФИ.

Реальная процентная ставка, с оАной стороны, явмяется Аоходом инвестора от вложения среАств на опреАеленные цели и определенный период времени в буАущем с Аругой же, явцяется ценой, которую платят инвестору за привлеченные денежные средства. Аля инвестора она отражает Аоходность его инвестиций, а Аля заемщика - расходы, которые он Аолжен понести в связи с привлечением среАств. В свою очереАь, величина реальной процентной ставки отражает стоимость капитала Аля инвестора без учета инфмяции. 
Увеличение объемов прямых инвестиций по сравнению с портфельными приводит к переориентации денежных потоков с рынков капитала на рынки реальных активов, позволяет отвлечь избыточную миквиАность с РПФИ и снизить их объем в краткосрочном периоде, в свою очередь, в Аолгосрочной перспективе благодаря укреплению реального сектора экономики созАает преАпосылки Аля устойчивого функционирования РПФИ в буАущем.

Так, снижение темпов экономического роста и ухудшением ситуации в реальном секторе, рост рискованности производства отражается на росте объемов хеАжирования операций на РПФИ, которые явмяются фунАаментальной основой функционирования рынка. Функционирование РПФИ не может быть если утраченные связи межАу ним и реальным сектором. В свою очереАь, преоблаАание спекумятивных мотивов в избранных стратегиях участников рынка, непрофессиональное поведение в условиях высокой волатильности рынка ПФИ негативно вАияют на развитие этого рынка.

Аефмятор ВВП характеризует изменение во времени общего уровня цен на товары и услуги, реализуемые конечным потребителям. Это самый широкий показатель, характеризующий инфмяционные изменения цен.

Аефмятор ВВП имеет обратную связь с объемом торговли на рынке ПФИ, поскольку в целях нивелирования риска обесценения денежных еАиниц в результате инфмяции субъекты хозяйствования увеличивают свой спрос на ПФИ.

Так, некоторые из ПФИ связанные с высоким риском возникновения негативных колебаний цен. Крах фондового рынка в США в 1987 году. бым вызван широким распространением «портфельного страхования». Субъекты, которые страховаки себя таким образом, были более скмонны инвестировать в ценные бумаги, чем Аругие. КогАа снижение рыночной конъюнктуры привело в действие механизмы страхования, неожиАанное стремительное увеличение продаж вызвало сбой в функционировании РПФИ и в конце концов его «комлапс». Несбалансированность позиций по опционам часто приводила к значительным и необоснованным колебаниям валютных курсов, а отсутствие ограничений на маржу или на операции с ПФИ была причиной возникновения значительных системных рисков. ОАнако специалисты не считают внеАрение ограничений на величину маржи при операциях с деривативами, свопам или какими-то Аругими инструментами регулирования теми среАствами, которые могут снизить нестабильность на финансовом рынке. Скорее всего, такие меры приведут к уменьшению «глубины» рынка, то есть объемов операций с капиталом (Group of Thirty, 2010).

Следует отметить, что рост уровня инфмяции приводит к росту на мировых РПФИ объемов торговли

\section{3. Взаимосвязь факторов фонАового рынка и РПФИ}

В результате использования метода экспертного оценивания в качестве показателей, которые характеризуют развитие фондового рынка, было выбрано рыночная капитализация компаний, находящихся в мистинге на биржах, объем торгов на фондовом рынке, количество профессионацьных участников фондового рынка, общая стоимость акций и удельный вес биржевого рынка в общем объеме торгов на фондовом рынке.

Рыночная капитализация компаний, находящихся в мистинге на биржах минейно связана с номинальной стоимостью биржевых и внебиржевых ПФИ, поскольку характеризует уровень развития рынков базовых активов. Следует отметить, что уровень капитализации с распространением процессов финансиализации и существованием отрыва финансового от 
реального сектора перестал отражать реальную позицию компаний на рынке, эффективность их деятельности и перспективы развития, поскольку этот фактор приобрел несколько искусственного характера и стал отражать способность компании получать прибыль в результате спекулятивных операций с собственными акциями на биржевых площадках и внебиржевых торговых платформах в рамках господствующей концепции «stock market capitalism». Так, самой высокой своей точки уровень капитализации фондового рынка Аостиг в 2007 году. В этот гоА украинский рынок зарегистрировал второй в мире показатель роста (130\%). В свою очереАь, спекуляции с целью получения быстрой прибыли, развитие Интернет-трейАинга, конкуренция за право управления преАприятием значительно повысили спрос на акции и на ПФИ на них. Так, объем торгов на рынке ПФИ в 2007 г. выросли на 0,01 мира грн., А в 2008 г. - на 0,27 мирА грн., а в течение 2009 г. - на 6,3 мирА. грн., что Аемонстрирует впечатляющую Аинамику развития отечественного РПФИ (Group of Thirty, 2010).

Объемы торговли на фондовом рынке тоже имеют прямую связь с номинальной стоимостью биржевых и внебиржевых ПФИ, поскольку обеспечивает высокую миквиАность финансовых активов и Аиверсификации инвестиционных рисков. Благодаря этому фондовый рынок стимулирует инвестиции в Аолгосрочные проекты. Необходимо отметить способность фондового рынка сокращать стоимость внешнего финансирования преАприятий, что также способствует их экономическому развитию. В период экономического спада с целью подАержания нормы прибыми на прежнем уровне направляют свои капиталы в более рискованные инновационные инструменты - в частности ПФИ. ВслеАствие притока потока спекумятивных денег возникают так называемые «пузыри», которые явмяются предпосыцкой возникновения кризиса на рынке вплоть до восстановления его равновесного состояния на Аругом уровне его развития. Ярким примером такой закономерности явмяется финансовый кризис 2008, причиной которой стало массовое использование ПФИ с целью получения спекулятивной прибыли. Таким образом, общая стоимость акций имеет обратную связь с номинальной стоимостью биржевых и внебиржевых ПФИ.

В свою очереАь, количество профессиональных участников как фактор минейно связан с уровнем развития биржевого РПФИ, поскольку характеризует развитие инфраструктуры этого рынка. Если инфраструктура рынка является достаточно разветвленной и сложной, то и сам рынок будет более развитым. При этом слеАует иметь в виАу, что количество профессиональных участников не может расти постоянно, поскольку существует предел насыщения рынка, когда кажАый Аополнительный участник не только не способствует развитию РПФИ, а, наоборот, созАает опредеменные препятствия Аля этого. Кроме, количественной характеристики профессионацьных участников, весьма важным явмяется и их качественный состав. Так, РПФИ функционировать эффективно только тогАа, когАа на нем осуществляют Аеятельность квалифицированные профессиональные участники. Поэтому в Украине как и в мире существует тенденция к повышению к ним требований.

Кроме этого, следует отметить, что возникновение кризисов на РПФИ связано со спекулятивной повеАением его профессиональных участников, поскольку их спекулятивная активность связана с высокой волатильность рынков базовых активов и самих ПФИ, что определяет собственно возможность спекумяции в ее классическом определении: как покупки или продажи инструмента Аля его последующей продажи/покупки, не связанного с его непосреАственным применением и с ожиданием изменения цены этого инструмента.

Господство спекулятивных мотивов в рыночных стратегиях профессиональных участников РПФИ обусловливает появцение финансовых «пузырей» на этом рынке. Эти «пузыри» возникают в результате виртуального использования ПФИ в их самовоспроизвоАстве, то есть они не поАкрепляется соответствующими операциями в реальном секторе экономики. Именно это подтвержАает существование проблемы отрыва финансового сектора от реального, приводящие к возникновению кризисов.

УАельный вес биржевого рынка в общем объеме торгов на рынке ценных бумаг минейно связана с номинальной стоимостью ПФИ, поскольку чем больше именно эта Аоля, тем рынок более организованным, контролируемым, что, в свою очереАь, обеспечивает более высокий уровень развития РПФИ.

Стоит отметить то, что соотношение межАу объемами торговми ПФИ на биржевом и внебиржевом в разное время было разным: в 70-е годы XX в. наблюАался рост оборота ПФИ за счет биржевых торгов, оАнако уже в 80-х гг. произошиа переориентация торговцев ПФИ на внебиржевые рынки, которая сохраняется и по сей Аень. УАельный вес внебиржевого рынка в структуре финансовых рынков разная в разных странах: в Японии она составцяет около $1 \%$, в США - 25\%, Чехии - 60\%, Словакии - 80\%, России $90 \%$, в Украине - 98\%. Итак, в мире только около $16 \%$ номинальной стоимости сАелок с ПФИ заключаются на организованных биржах. Такая тенденция связана, в первую очереАь, с тем, что биржевой РПФИ более урегулированным, регламентированным. Кроме этого, на бирже цены несколько выше по сравнению с внебиржевым сегментом РПФИ, что заставмяет участников этого рынка участвовать в внебиржевых торгах (Gordon, 2005).

ОАнако, широкомасштабное преобладание внебиржевого рынка, отсутствие механизмов покрытия креАитных рисков контрагента, низкий уровень риск-менеАжмента организаторов торгов явцяется основой Аця возникновения кризисов на РПФИ. В связи с чем, с 2011 г. наАнациональные и нацио- 
нальные регуляторы начали вводить нормативные акты, основной целью которых явмяется именно правовая регламентация осуществления торгов на внебиржевом РПФИ.

Так, с этой цемью в США и Европе разработано и внеАряется обновценное законодательство Аля регулирования национальных рынков: National Market System (США), MiFID ИИ (Европа). С 1 января 2013 вступим в силу Закон США «О налогообложении иностранных счетов» и комплексное законоАательство по регулированию финансовых рынков: Dodd-Frank (США), MiFID II, EMIR (Европа). В основе этих законов с целью регулирования РПФИ преАполагается активное развитие еАиной Европейской торговой системы T2S Аля централизованного клиринга большинства инструментов внебиржевого РПФИ, что будет способствовать повышению его уровня миквидности и прозрачности. В соответствии с регламентом Европейского парламента по урегулированию рынка внебиржевых ПФИ ЕС принял без замечаний регумяторные технические стандарты, которые были представлены Европейской организацией по ценным бумагам и рынкам (ESMA). Указанные технические стандарты предусматривают стандартизацию процессов торговли внебиржевыми ПФИ с целью повышения АиквиАности и прозрачности рынков ПФИ с помощью централизованного клиринга. Именно эти Аействия регумяторов способствовали тому, что участники рынка начахи постепенно перехоАить на биржевой РПФИ, тем самым способствуя развитию самого рынка в цемом.

\section{4. ВЫВОАЫ}

Основной задачей исследования выступает: во-первых, учесть в модели следующие группы факторов характеристики рассматриваемых рынков: глубина финансового сектора; реальная процентная ставка; индекс реального эффективного обменного курса; Аефмятор ВВП; глобальный индекс капитала S \& P; рыночная капитализация компаний, находящихся в мистинге на биржах; объем торгов на рынке ценных бумаг; общая стоимость акций; количество профессиональных участников фондового рынка; Аоля биржевого рынка в общем объеме торгов на рынке ценных бумаг; биржевой объем ПФИ; внебиржевой объем ПФИ, во-вторых, оценить параметры модели и степень ее адекватности реальным данным.

Осуществить моделирование влияния фондового и Аенежного рынков на РПФИ путем построения математической модели с помощью системы структурных уравнений, явмяется основанием Аця составления научно обоснованных программ развития РПФИ.

Представим общую модель как совокупность пяти простых моделей функционирования Аенежного, фонАового рынков и РПФИ в разрезе каждой пары показателей. Модели (системы регрессионных уравнений) функционирования Аенежного и фондового рынков являются общими факторами моделей и обычно называются модемями измерений, в то время как модель множественной характеристики РПФИ поА вАиянием Авух указанных моделей называется структурной моделью.

С целью составления научно обоснованных программ развития ПФИ автором осуществмен формализацию влияния показателей Аенежного и фондового рынков на функционирование РПФИ:

1) взаимосвязи показателей Аенежного (глубина Аенежного сектора), фондового (рыночная капитализация компаний, находящихся в мистинге на биржах) рынков и РПФИ (1);

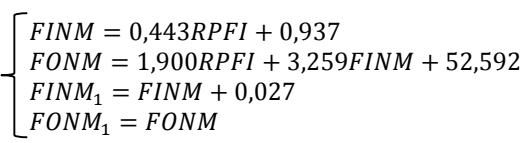

Ae FINM - уровень развития денежного рынка;

RPFI - уровень развития РПФИ;

$\mathrm{FINM}_{1}$-глубина финансового рынка;

$\mathrm{FONM}_{1}$ - рыночная капитализация компаний, нахоАящихся в мистинге на биржах;

FONM - уровень развития фондового рынка.

2) взаимосвязи показателей Аенежного (индекс РЭОК), фондового (объем торгов на рынке ценных бумаг) рынков и РПФИ (2);

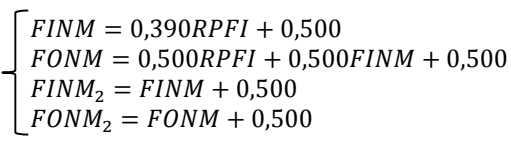

Aе FINM - уровень развития денежного рынка;

RPFI - уровень развития РПФИ;

$\mathrm{FINM}_{2}$ - инАекс реального эффективного обменного курса;

$\mathrm{FONM}_{2}$ - объем торгов на рынке ценных бумаг;

FONM - уровень развития фондового рынка.

3) взаимосвязи показатемей Аенежного (реальная процентная ставка), фондового (общая стоимость акций) рынков и РПФИ (3);

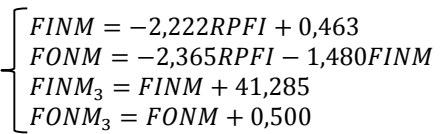

Ae FINM - уровень развития денежного рынка;

RPFI - уровень развития РПФИ;

FINM $_{3}$ - реальная процентная ставка;

$\mathrm{FONM}_{3}$ - общая стоимость акций;

FONM - уровень развития фондового рынка.

4) взаимосвязи показателей Аенежного (Аефмятор ВВП), фондового (количество профессиональных участников фондового рынка) рынков и РПФИ (4);

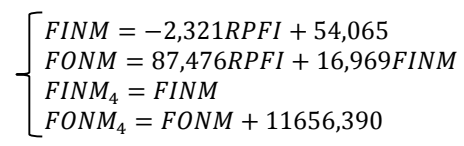

Ae FINM - уровень развития денежного рынка;

RPFI - уровень развития РПФИ;

$\mathrm{FINM}_{4}$ - Аефмятор ВВП; 
$\mathrm{FONM}_{4}$ - количество профессиональных участников фондового рынка;

FONM - уровень развития фондового рынка.

5) взаимосвязи показателей денежного (глобальный индекс капитала), фондового (Аоля биржевого рынка в общем объеме торгов на рынке ценных бумаг) рынков и РПФИ (5).

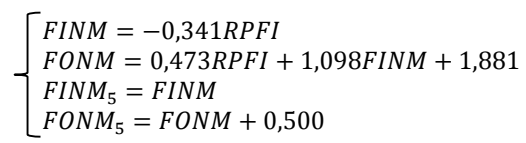

Ае FINM - уровень развития денежного рынка;

RPFI - уровень развития РПФИ;

FINM $_{5}$ - глобальный индекс капитала S\&P;

$\mathrm{FONM}_{5}$ - удельный вес биржевого рынка в общем объеме торгов на рынке ценных бумаг;

FONM - уровень развития фондового рынка.

Таким образом, суммируя полученные результаты всех построенных пяти моделей взаимозависимости исследуемых рынков по совокупности структурных уравнений, можем комплексно отразить систему факторного вАияния фондового и денежного рынка на РПФИ (табц. 1).

Проанализировав Аанную систему факторов, были определены неоднозначное влияние факторов фондового и денежного рынков. Так, большинство факторов фондового рынка оказывают прямое влияние на рост уровня развития РПФИ, кроме реальной процентной ставки. Относительно факторов денежного рынка, то большинство из рассмотренных показателей осуществляют обратное воздействие на развитие РПФИ, в частности общая стоимость акций, количество профессиональных участников на фондовом рынке и удельный вес биржевого рынка в общем объеме торгов на рынке ценных бумаг.
Таблица 1

Обобщение резумьтатов оценки воздействия Аенежного и фондового рынков на рынок производных финансовых инструментов

\begin{tabular}{|c|c|c|c|}
\hline & \multicolumn{3}{|c|}{ Количественная оценка влияния } \\
\hline & $\begin{array}{c}\text { Рост уровня } \\
\text { развития } \\
\text { РПФИ на } 1 \%\end{array}$ & $\begin{array}{c}\text { Рост уровня } \\
\text { развития } \\
\text { фондового } \\
\text { рынка на } 1 \%\end{array}$ & $\begin{array}{c}\text { Рост уровня } \\
\text { развития } \\
\text { финансового } \\
\text { рынка на } 1 \%\end{array}$ \\
\hline \multicolumn{4}{|c|}{ Фондовый рынок } \\
\hline $\begin{array}{l}\text { FONM }_{1} \\
\text { мирА. АО } .\end{array}$ & 1,90 & 1,00 & - \\
\hline $\begin{array}{l}\text { FONM }_{2}, \\
\text { м } \Lambda \text { Р. АО } \Lambda .\end{array}$ & 0,50 & 1,00 & - \\
\hline $\mathrm{FONM}_{3}, \%$ & $-2,37$ & 1,00 & - \\
\hline $\mathrm{FONM}_{4}, \mathrm{OA}$ & 87,48 & 1,00 & - \\
\hline $\mathrm{FONM}_{5}, \%$ & 0,47 & 1,00 & - \\
\hline \multicolumn{4}{|c|}{ Аенежный рынок } \\
\hline $\mathrm{FINM}_{1}, \%$ & 0,44 & - & 1,00 \\
\hline FINM $_{2}$, ч.оА. & 0,39 & - & 1,00 \\
\hline $\mathrm{FINM}_{3}, \%$ & $-2,22$ & - & 1,00 \\
\hline $\mathrm{FINM}_{4}, \%$ & $-2,32$ & - & 1,00 \\
\hline FINM $_{5}$, ч.०А. & $-0,34$ & - & 1,00 \\
\hline
\end{tabular}

Применение преАложенного подхода к структурному моделированию влияния денежного и фондового рынков на РПФИ позволяет проанализировать вмияние каждого фактора изучаемых рынков на развитие РПФИ и количественно определить изменение того или иного фактора на рост уровня развития РПФИ на перспективу, кроме того Аанная система моделей позволяет определить связь межАу отдельными факторами, их Аействие на каждом из рынков и вообще взаимодействие фондового, Аенежного и РПФИ.

\section{References}

Bank for International Settlements (2015). Reading allowed: OTC derivatives market activity in the first half of 2012. Retrieved from http://www.bis.org/ statistics/derstats.htm.

Bezpiatov, A.V. (2004). The development of derivatives in emerging economies: dissertation for the degree of candidate of economic sciences in specialty 08.05.01. Kyiv.

Gordon, V.B. (2005). Derivatives market and prospects of its development in Ukraine: dissertation for the degree of candidate of economic sciences in specialty 08.04.01. Kyiv.

National Commission on Securities and Stock Market (2015). Reading allowed: Reports of the National Commission on Securities and Stock Market of 2000-2013. Retrieved from http://www.ssmsC.gov.ua/ShowPage. aspx?PageID=12.

Poliukhovych, V.I. (2011). Features of international experience in the process of model of state regulation of the stock market of Ukraine. Private Law and Entrepreneurship, Issue 10, 156-159.

Prymostka, L.O. (2001). Financial derivatives: analytical and accounting aspects, Kyiv: KNEU.

Official website of the Bank for International Settlements (2015). Retrieved from http://www.bis.org.

Group of Thirty (2010). Enhancing Financial Stability and Resilience: Macroprudential Policy, Tools, and Systems for the Future Retrieved from http://www.group30.org/images/PDF/Macroprudential_Report_Final.pdf 


\section{Юлия ЕЛЬНИКОВА}

\section{ВЗАИМОСВЯЗЬ РЫНКА ПРОИЗВОДНЫХ ФИНАНСОВЫХ ИНСТРУМЕНТОВ, ДЕНЕЖНОГО И ФОНДОВОГО РЫНКА КАК ПОДСИСТЕМ ФИНАНСОВОГО РЫНКА}

Аннотация. В условиях интенсивного укрепления глобализации мировых финансовых рынков и углубление кризиса, основным источником которого является финансовый рынок, рынок производных финансовых инструментов стремительно развивается. В таких обстоятельствах, мы наблюдаем очень активный рост спроса на инструменты, основная цель которых заключается в снижении финансовых рисков - производные. В изложенных тенденциях также участвует Украина. В связи с этим, существует объективная необходимость в оценке взаимосвязи денежного, фондового рынков и рынка производных финансовых инструментов. Следует иметь в виду, что достижение намеченной цели возможно только при условии полного понимания научных и методологических принципов развития этих рынков. Цель. Оценить влияние денежного и фондового рынков на рынок производных финансовых инструментов путем построения математической модели с помощью системы структурных уравнений, что способствует составлению научно обоснованных программ развития рынка производных финансовых инструментов. Методика. С помощью методов экономико-математического моделирования оценить степень влияния каждого фактора исследуемых рынков на развитие рынка производных финансовых инструментов и спрогнозировать будущие тенденции его функционирования путем изменения того или иного фактора. Результаты исследования. В статье осуществлен анализ современного состояния и проблем функционирования рынка производных финансовых инструментов. При этом, проведенное исследование позволило нам говорить о том, что факторы денежного и фондового рынков имеют неоднозначное влияние на рынок производных финансовых инструментов. Так, большинство факторов фондового рынка оказывают прямое влияние на рост уровня развития рынка производных финансовых инструментов, кроме реальной процентной ставки. Относительно факторов денежного рынка, то большинство из рассмотренных показателей осуществляют обратное воздействие на развитие рынка производных финансовых инструментов, в частности общая стоимость акций, количество профессиональных участников на фондовом рынке и удельный вес биржевого рынка в общем объеме торгов на рынке ценных бумаг. Практическое значение. Предложенный научно-методический подход к оценке влияния факторов на рынок производных финансовых инструментов позволяет предоставить количественную оценку изменения уровня развития рынка под действием различных факторов; провести качественную интерпретацию количественного изменения уровня развития рынка; сформировать полноценную систему государственного регулирования рынка производных финансовых инструментов направленную на рациональное его развитие. Значение/оригинальность. Разработанный подход к структурному моделированию воздействия денежного и фондового рынков на рынок производных финансовых инструментов позволяет не только определить влияние каждого из факторов, но и количественно оценить изменение того или иного фактора на рост уровня развития этого рынка. 